\title{
Requirements for Servitization in Manufacturing Service Ecosystems
}

\author{
Results of a Requirements Analysis \\ of Four Manufacturing Use Cases
}

\author{
Stefan Wiesner ${ }^{1}$, Michele Sesana ${ }^{2}$, Sergio Gusmeroli ${ }^{2}$, and Klaus-Dieter Thoben ${ }^{1}$ \\ ${ }^{1}$ Bremer Institut für Produktion und Logistik, Hochschulring 20, 28359 Bremen, Germany \\ ${ }^{2}$ TXT e-Solutions S.p.A., Via Frigia 27, 20126 Milano, Italy \\ \{wie, tho\} @biba.uni-bremen. de \\ \{michele.sesana, sergio.gusmeroli\}@txtgroup.com
}

\begin{abstract}
As tangible products can be easily copied and customers ask for individual solutions, the European manufacturing industry increasingly bundles their products with associated services to so called "Extended Products" (EP). Missing competencies for this servitization have to be acquired by involving partners from the companies' environment, the "Manufacturing Service Ecosystem" (MSE). However, traditional manufacturers lack the appropriate models, methods and tools for collaborative innovation, development and provision of EP. This paper presents the results of a requirements analysis of four manufacturing use cases that indicates the need for support in the area of servitization and collaboration in MSE.
\end{abstract}

Keywords: Servitization, Manufacturing Service Ecosystem, Requirements Engineering, Collaborative Tools, MSEE Integrated Project.

\section{Introduction}

The gap of the technological advance of the European manufacturing industry is currently shrinking, reducing the competitiveness of traditional business strategies like cost leadership and differentiation [1]. On the one hand, even innovative tangible products can be easily copied and are no longer usable as a unique selling proposition. On the other hand, new customer needs emerge that cannot be satisfied by a traditional product [2]. To understand and answer the customers' problem, manufacturers begin to add services to their products to create holistic and individual solutions and benefits. Such an offering of complementary product and service components is commonly named as a Product-Service System, or "Extended Product" (EP) [3]. This servitization strategy starts with simple services that support the functionality of the product, like spare part delivery, extends over services that ensure the availability of the product, like predictive maintenance and culminates in selling the benefits of product application as a service in the sense of an operator model [4]. 
However, following a servitization strategy, from integrated product and service idea generation to realization and commercialization, requires additional competencies compared to the manufacturing of a tangible product. The involvement of the customers as partners to identify their needs and collaborative arrangements with other enterprises like service providers become more and more important [5,6]. As the solution for the customer will be configured individually, the required competencies will change each time. A promising concept to tackle the challenges of servitization is the "Manufacturing Service Ecosystem" (MSE). As a non-hierarchical form of collaboration, it allows the incorporation of new partners according to changing requirements for a solution [7]. Manufacturing enterprises are typically neither prepared for servitization, nor for collaboration in dynamic non-hierarchical networks like MSE. They are missing the right models and methods for service innovation, the required physical resources, organizational structures, as well as IT tools. In order to support the manufacturing industry in this transformation, their requirements for the needed models, methods and tools have to be determined.

This paper presents the results of a requirements analysis of four use cases from different branches of the manufacturing sector. First, the theoretical background on servitization and collaboration in MSE is presented in chapter two. Following, chapter three describes the methodology for the requirements analysis. The resulting requirements for the support of servitization in MSE in the manufacturing industry are specified in chapter four. Finally, a conclusion and outlook on the development of solutions based on the requirements is given.

\section{Theoretical Background}

\subsection{Servitization}

The demand for high individual solutions has led to the situation that satisfying customer needs only through tangible products is no longer possible [8]. Value adding services are combined with the tangible product to Extended Products. This process has first been called "servitization" by Vandermerwe and Rada [9]. They describe the increasing customer demand-driven offering of product-service "bundles" (consisting of goods, services, support, knowledge and self service) by manufacturing enterprises to create a competitive edge.

Different options for servitization can be identified, creating a number of challenges for the manufacturer of the tangible product. Below, possible options for servitization are described along with the inherent challenges [10]:

- New combinations of existing products with existing services

The tangible product can be combined with already existing services. In this case, the manufacturer has to be able to identify promising services on the market and create the necessary interfaces for combination with the product.

- New services for existing products

A new service can be developed for the existing product. Therefore competencies for service innovation, development and delivery are required in addition to the manufacturing of the tangible product. 
- New products for existing services

The manufacturer can also decide to develop a new product for an existing service on the market. In this case, the product design has to be aligned with the service specification to ensure interoperability.

\section{- Combinations of new products with new services}

Finally, the tangible product and the services can be developed in parallel to create an integrated solution. This requires competencies in both product and service design, but also the ability to merge the results from both domains.

The analysis of servitization options shows the challenges and additional competencies required for the manufacturer of the tangible product. Besides the existing experiences in developing, producing and maintaining a tangible product, a service life cycle (SLM) has to be aligned and managed as well. But manufacturing enterprises are usually inexperienced in service ideation, design and delivery and fear the competition outside their natural domain [11]. Thus, they require support to successfully align and manage the phases of the SLM:

- Service ideation

- Service specification and design

- Service implementation and testing

- Service delivery and decommission

Nevertheless, the complexity behind the provision of services and flexibility required at the same time leads to the outsourcing of services [12]. Therefore, the implementation of new organizational models, based on collaboration between product and service providers and the customer is also required. The Manufacturing Service Ecosystem described in the next section is such a model.

\subsection{Manufacturing Service Ecosystems}

The currently dominating hierarchical supply chains in the manufacturing sector are not supporting the transformation from a tangible product perspective towards an Extended Product perspective. More flexible arrangements between manufacturers and other partners are required. In parallel with servitization, collaboration models in manufacturing will have to change to support the innovation of Extended Products, the required organizational structures and processes for their provision and the appropriate supporting tools and techniques.

As a more flexible and less hierarchical form of collaboration for servitization, the establishment of a Manufacturing Service Ecosystem is proposed. The concept of comparing the business environment of an enterprise to a biological ecosystem has been introduced by Moore [13]. In such a Business Ecosystem, members who might become new business partners or new customers are able to share knowledge, innovate and collaborate together, interact or connect with each other, design new products, communicate globally and develop projects [14]. Within this ecosystem, different and heterogeneous entities like big OEMs, SMEs, universities, research centers, individual professionals, employees, citizens and consumers etc. are left free to 
evolve and to network as they like, just following the market evolutionary law that it is the fittest species which survives. The main characteristics of a Business Ecosystem include complexity, self-organization, emergence, co-evolution and adaptation [15].

The Manufacturing Service Ecosystem concept builds on the Business Ecosystem idea, but adds characteristics typical for the servitization of manufacturing. Innovation in this environment is driven by the fact that business opportunities might be generated and identified within the MSE and not brought by the outside market. This is due to the customers also being part of the ecosystem and participating in value cocreation: "The MSE is a non-hierarchical form of collaboration where various different organizations and individuals work together with common or complementary objectives on new value added combinations of manufactured products and productrelated services. This includes the promotion, the development and the provision of new ideas, new products, new processes or new markets. Future Internet architectures and platforms enable the active participation of all stakeholders in all the phases of the product and service life cycle." [10]

The MSE concept features four dimensions, which have to be supported with the appropriate models, methods and tools:

- Organisational dimension

How to describe the constituting elements of a MSE - its participants and roles?

- Componential dimension

How to manage the tangible and intangible assets and resources of the MSE?

- Functional dimension

How to support the execution of inter-organizational processes in the MSE?

- Governance dimension

How to implement the principles, policies and governance rules for the MSE?

There is little previous work providing guidelines, tools or techniques that can support manufacturing enterprises for the above issues in MSE. According to Baines et al., "the principal research need is to engineer tools or techniques that practitioners can apply to help in service design, organisational design and organisational transformation" [12]. Therefore, the requirements of the manufacturing industry towards these supporting tools and techniques have to be determined.

\section{Methodology}

The requirements analysis in this paper has been conducted on the basis of the servitization use cases from four different manufacturing enterprises. The cases come from different branches of the European manufacturing sector and represent SME's as well as large OEM's. In particular, the cases represent:

- A Dutch OEM of consumer electronics

- An Italian OEM of white goods

- A Belgian SME in the garments sector

- A Spanish SME in the machine tool sector 
Due to the high innovation potential and complexity of servitization in MSE, manufacturing enterprises might not be immediately aware of the required supporting models, methods and tools. Therefore, a collaborative methodology has been applied, supported by Serious Gaming (see Fig. 1).

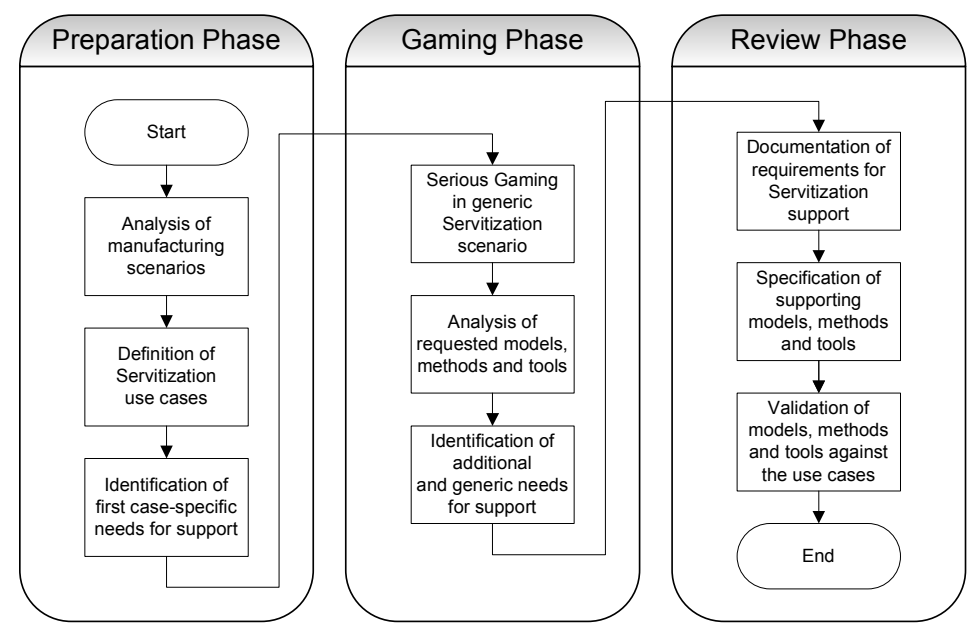

Fig. 1. Methodology for Requirements Analysis

The methodology is based on a three phase approach presented by Zarvic et al. [17]. In a preparation phase, based on the analysis of the manufacturing scenarios, concrete servitization use cases were determined for each enterprise. A workshop featuring focus group and brainstorming sessions has identified first case-specific needs for supporting models, methods and tools.

In order to meet the necessity of a non-limiting methodology, Serious Gaming was adopted for the second phase. The game used for this purpose is SECONDS [17], a game which simulates a complex business environment that consists of several systems, and allows the end users to reflect upon their own internal processes, even though playing in a common generic scenario. The main objective of the scenario is to develop and sell a car with mobility services. In order to provide this value proposition, the players need to collaborate in their ecosystem. The game is lead by a facilitator, to which the players are able to report missing or insufficient support for their servitization processes. An analysis of these reports has delivered additional and generic needs for supporting models, methods and tools.

During the review phase, the needs of the manufacturing enterprises are analysed and documented as a requirements list for servitization support. These requirements have then been used for the final specification of the supporting models, methods and tools for servitization. The specification has been validated against the servitization use cases and the final developments will be evaluated in pilot implementations at the four manufacturing enterprises. 


\section{Results of the Requirements Analysis}

For the analysis, the requirements determined for supporting the four servitization use cases in MSE have been combined with the additional requirements coming from the generic Serious Gaming manufacturing scenario. The documented requirements have been assigned to the eight areas described for the service life cycle and the MSE dimensions in chapter 2 . The results of this aggregation are listed below in Table 1.

Table 1. Aggregated List of Requirements for servitization in MSE

\begin{tabular}{|c|l|c|c|c|}
\hline$\#$ & Aggregated Requirements per Area & $\mathbf{C R}^{\mathbf{1}}$ & $\mathbf{G R}^{\mathbf{2}}$ & $\boldsymbol{\Sigma}$ \\
\hline 1. & Service delivery and decommission & 13 & 8 & $\mathbf{2 1}$ \\
\hline 2. & Service specification and design & 14 & 3 & $\mathbf{1 7}$ \\
\hline 3. & MSE - componential dimension & 7 & 4 & $\mathbf{1 1}$ \\
\hline 4. & Service implementation and testing & 7 & 3 & $\mathbf{1 0}$ \\
\hline 5. & MSE - organizational dimension & 5 & 3 & $\mathbf{8}$ \\
\hline 6. & MSE - functional dimension & 5 & 2 & $\mathbf{7}$ \\
\hline 7. & MSE - governance dimension & 6 & - & $\mathbf{6}$ \\
\hline 8. & Service ideation & 3 & 2 & $\mathbf{5}$ \\
\hline
\end{tabular}

For the service life cycle, many requirements can be assigned to the delivery and decommission area, which indicates a lack of knowledge in the manufacturing enterprises on how to provide additional services to their tangible products. The main supporting tool developed will provide ecosystem members with a way to browse and search service offerings from several federated marketplace instances. As a service has to be designed before it can be delivered, service specification and design is another important aspect. Therefore, a collaborative service engineering methodology is being developed, comprising methods for service modeling and platforms for service development. In service implementation and testing, the requirements have led to the development of a feedback management tool to collect information on the usability of a service from the customers' viewpoint. Finally, ideation is the last service area needing support. Here, a tool to support service idea generation is developed, allowing sharing ideas in the ecosystem and validation by other MSE members. The relatively low number of requirements in this area should not lead to the impression that the topic of service ideation is not important for the manufacturing enterprises. However, due to the low experience in this field, it was not easy for the use cases to phrase concrete requirements.

For the MSE in general, an Innovation Ecosystem Platform (IEP) is developed. The IEP is the backbone of the MSE Service-System, providing a platform to manage the MSE in terms of level of activity, interactions, roles and flow of information between its members. In the componential dimension, a model to define the tangible and intangible assets in the MSE, to be able to compose the right assets for a desired

\footnotetext{
${ }^{1}$ Mentioned as requirement for the specific servitization case.

${ }^{2}$ Mentioned as general requirement for the manufacturing industry.
} 
product-service combination will be included. The need for support in the organizational, functional and governance dimensions of the MSE requires the developments of a methodology for management and governance of MSEs, which also supports the set-up of a Virtual Manufacturing Enterprise (VME) for a specific Extended Product business opportunity.

The ranking of the areas for support of servitization in MSE should not be misunderstood as a prioritization of needs. It rather shows where the manufacturing enterprises were able to communicate concrete requirements and where it was hard for them to clearly express their need for support. The models, methods and tools developed on the basis of these requirements will be tested and verified by the use cases, which may lead to more and detailed requirements in the future.

\section{Conclusion}

The European manufacturing in industry is under pressure to rethink their traditional strategies of cost leadership or differentiation of tangible products. Servitization has been identified as a promising approach to satisfy new customer demands and prevail against competitors, implying the combination of tangible products and intangible services to Extended Products. The required additional competencies for the innovation, development and provision of EP have to be selected individually for each customer demand. This arrangement can be facilitated by the introduction of the Manufacturing Service Ecosystem concept.

However, manufacturing enterprises are typically experienced in the production of physical goods in fixed supply chains. Adding advanced services to their products and collaborating in a flexible ecosystem environment creates new challenges for them. The analysis of the requirements collected from four manufacturing companies clearly shows the need for support for servitization and MSE collaboration. The collected requirements have been used for the specification of supporting models, methods and tools for servitization in MSE, which are now being developed. In a future work, the developments will be applied to the real servitization use cases of the manufacturing companies and evaluated for their benefit in an MSE environment.

Acknowledgements. This work has been partly funded by the European Commission through the FoF-ICT Project MSEE: Manufacturing SErvice Ecosystem (No. 284860), which is fostering the research in this area and will develop the final MSE concept and several practical implementations in the manufacturing industry until 2014. The authors wish to acknowledge the Commission and all the MSEE project partners for their contribution.

\section{References}

1. Lindič, J., Bavdaž, M., Kovačič, H.: Higher growth through the Blue Ocean Strategy: Implications for economic policy. Research Policy 41(5), 928-938 (2012) ISSN 0048-7333

2. Gebauer, H., Gustafsson, A., Witell, L.: Competitive advantage through service differentiation by manufacturing companies. Journal of Business Research 64(12), 1270-1280 (2011) ISSN 0148-2963 
3. Seifert, M., Thoben, K.-D., Eschenbaecher, J.: Mechanisms to conduct Life Cycles of Extended Products. In: Hesselbach, J., Herrmann, C. (eds.) Functional Thinking for Value Creation, Proceedings of the 3rd CIRP International Conference on Industrial Product Service Systems, pp. 39-43. Springer, Heidelberg (2011)

4. Meier, H., Roy, R., Seliger, G.: Industrial Product-Service Systems-IPS2. CIRP Annals Manufacturing Technology 59, 607-627 (2010)

5. Hakanen, T., Jaakkola, E.: Co-creating customer-focused solutions within business networks: a service perspective. Journal of Service Management 23(4), 593-611 (2012)

6. Windahl, C., Lakemond, N.: Integrated solutions from a service-centered perspective: Applicability and limitations in the capital goods industry. Industrial Marketing Management 39(8), 1278-1290 (2010) ISSN 0019-8501

7. Wiesner, S., Westphal, I., Hirsch, M., Thoben, K.-D.: Manufacturing Service Ecosystems Towards a new model to support service innovation based on Extended Products. In: Emmanouilidis, C., Taisch, M., Kiritsis, D. (eds.) APMS 2012, Part II. IFIP AICT, vol. 398, pp. 305-312. Springer, Heidelberg (2013)

8. Johnston, R., Clark, G.: Service operations management: improving service delivery. Prentice Hall, Financial Times (2008)

9. Vandermerwe, S., Rada, J.: servitization of Business: Adding Value by Adding Services. European Management Journal 6(4), 314-324 (1988)

10. Wiesner, S., Winkler, M., Eschenbächer, J., Thoben, K.-D.: Strategies for extended product business models in manufacturing service ecosystems. In: Meier, H. (ed.) ProductService Integration for Sustainable Solutions. LNPE, vol. 6, pp. 239-250. Springer, Heidelberg (2013)

11. Martinez, V., Bastl, M., Kingston, J., Evans, S.: Challenges in transforming manufacturing organisations into product-service providers. Journal of Manufacturing Technology Management, 21(4), 449-469 (2010)

12. Baines, T., Lightfoot, H., Benedettini, O., Kay, J.: The servitization of manufacturing: A review of literature and reflection on future challenges. Journal of Manufacturing Technology Management 20(5), 547-567 (2009)

13. Moore, J.: Predators and Prey: The New Ecology of Competition. Harvard Business Review 71(3), 75-83 (1993)

14. Tapscott, D., Williams, A.: Macrowikinomics: New Solutions for a Connected Planet. Penguin Group, USA (2012) ISBN 9781591844280

15. Zhang, J., Fan, Y.: Current state and research trends on business ecosystem. In: IEEE International Conference on Service-Oriented Computing and Applications (SOCA), December13-15 (2010)

16. Wiesner, S., Peruzzini, M., Doumeingts, G., Thoben, K.D.: Requirements Engineering for servitization in Manufacturing Service Ecosystems (MSEE). In: The Philosopher's Stone for Sustainability, pp. 291-296. Springer, Heidelberg (2013)

17. Zarvić, N., Duin, H., Seifert, M., Thoben, K.D., Bierwolf, R.: Collecting end user requirements playfully. In: Proceedings of the 15th International Conference on Concurrent Enterprising, Leiden, NL, pp. 22-24 (2009) 